\title{
Modernization Versus Dependency Approaches to Sustainable Development--Based on the UN Report 2019
}

\author{
Siyuan Deng ${ }^{1, *}$, Jingxing Zhang ${ }^{1}$ \\ ${ }^{1}$ School of Business Administration, Southwestern University of Finance and Economics
}

\begin{abstract}
The essay tends to focus on the investigation into the changing sustainable development trend. It is important to know which areas have seen the greatest progress and which areas have stalled or even regressed around the globe. The researchers will compare and combine the modernization theory and dependency theory to figure out the potential factors which result in the different levels of achievement between all the 17 sustainable development goals (SDG). The researcher team are more likely to adopt both qualitative method and quantitative method to ensure the accuracy of the conclusion. In addition, due to the fact that the primary data related to this topic is too broad to obtain, the scientific group will mostly employ secondary data from the United Nations to carry out the research. Most of the data in the essay are from various United Nations documents and reports to ensure the authenticity and objectivity of the data. It allows the researchers to pay more attention on the specific analysis. Lastly, the goal of this paper is to find out the basic laws of sustainable development by looking for the unique representative parts of the 17 SDG goals (Basic education, Food safety, Life below water, etc.) and analysing their development trends in the past few years. In addition, the researchers tend to work out suggestions and solutions to those problems.
\end{abstract}

\section{INTRODUCTION}

\subsection{Background and Context}

The UN's 2030 goal is only a decade away, and sustainable development worldwide is still far from reaching it. Although countries have made great progress in some areas, some developing countries are still at risk of being left behind. And this is absolutely and undoubtedly contrary to the purposes and ideals of the United Nations. More worryingly, recent trends are not even moving in the right direction in several ways that have a cross-cutting impact on the entire 2030 Agenda. Four in particular fall into this category: the increase in inequality, climate change, the loss of biodiversity and the increasing amount of waste generated by human activities, which the capacity to deal with has outstripped the capacity to do so. Crucially, recent analysis suggests that a number of negative trends herald a trend across negative tipping points that will lead to dramatic and irreversible changes in the state of the Earth system on a time scale. Each country must respond to its own conditions and priorities while breaking the current practice of development first and cleaning up afterwards. Achieving a universal shift to sustainable development over the next decade depends on realizing countryspecific innovative approaches at the same time. In the next 10 years, the whole world ought to implement strictly the idea "Leave no one behind". Still, there is hope. Human well-being does not need to depend on intensive resource use, nor does it need to exacerbate or consolidate inequality and deprivation. Scientific knowledge enables us to identify keyways to break this pattern, and many examples around the world show that it is possible.

\subsection{Proposed Research Questions}

Overview: there are many fields that we made great progress, but some other areas have stagnated or deteriorated. Our group tends to choose 3 of the 17 SDGs to carry out analysis. The following ones are the most representative:

1.Children Education: Why it achieved a lot and what is the future vision?

2.Equality in Income: The changing trend of inequality and what is the connection with the economic growth?

3.Climate Change: Why the part have stalled or even regressed?

\section{MATERIALS \& METHODS}

\subsection{Secondary Data}

In this research, we mostly use secondary data instead of primary data. This is because the research on sustainable economic development is very complete, whether it is academia or the United Nations. Subject information and data have become systematized. We only need to find out the core concepts that are overwhelmed by

* Corresponding author: siyuandeng0327@163.com 
information. It may be difficult for us researchers to do experiments or other things to obtain raw data. Therefore, we tend to use some auxiliary data that other people have done before, by following their survey schedule. However, this does not mean that I will rely entirely on the research of others. We will also try our best to get some raw data to enhance the logic of this paper.

\subsection{Descriptive Data}

After careful comparison, we finally chose to use more descriptive data. This allows the research group to describe the subject's research objects in a more detailed and objective manner without affecting the research. This is especially important for social sciences that are more realistic and logical. More importantly, descriptive materials allow researchers to collect more data on a large scale. SPSS played an important role in the data collection and analysis of this study. We have established relevant models through case analysis and content research for different countries (such as developed and underdeveloped countries, core regions and marginal regions), and combined modernization theory with dependency theory, and finally explored the promising and exercisable trend of sustainable development.

\section{COLLECTED DATA \& RESULTS}

\subsection{Graphics of Changing Trend of The Children Education}

We normally choose both parts of developed countries and developing countries as control group.

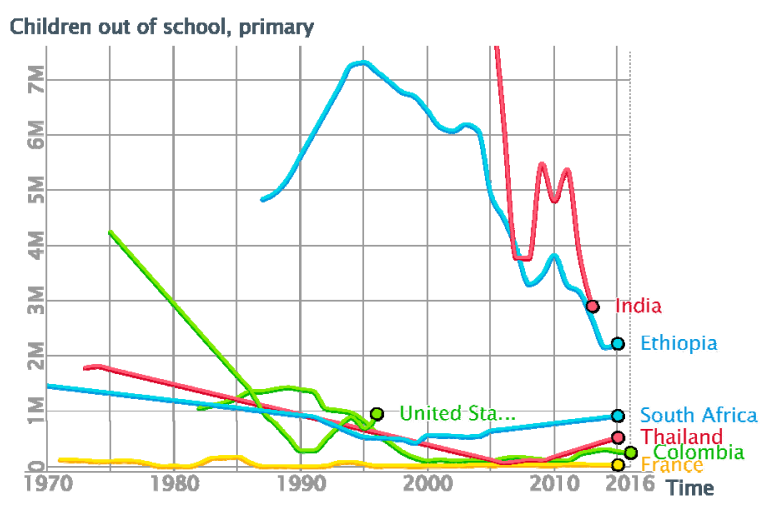

Fig. 1. Graphic of the children out of school, primary. (Source: Gapminder Tools)

Above is the line chart about the relationship between time and children out of school, primary. It can be seen that many countries have seen a long-term decline in child dropout rates. Below is the chart about expenditure per student, primary ( $\%$ of GDP per person), which can demonstrate the importance that major countries attach to basic education in the world. This is a powerful tool to measure to investigate the development trend of basic education.

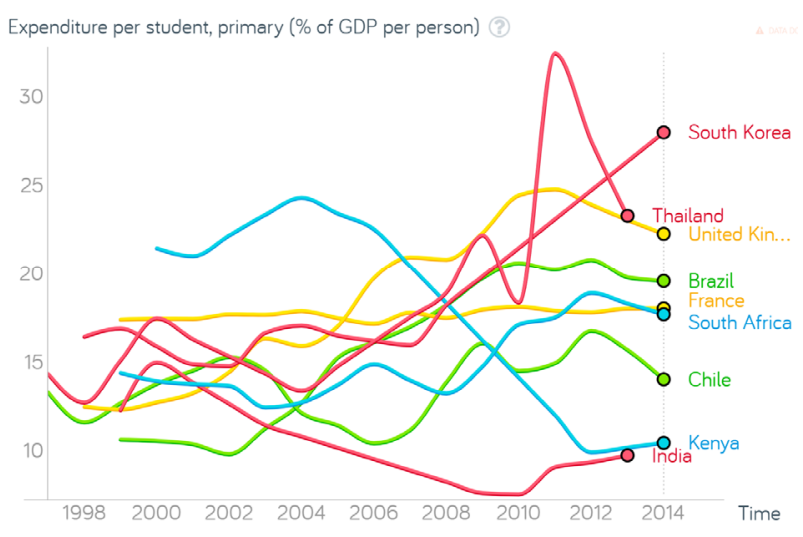

Fig. 2. Graphic of the expenditure per student, primary. (Source: Gapminder Tools)

\subsection{Graphics of Changing Trend of The Equality in Income}

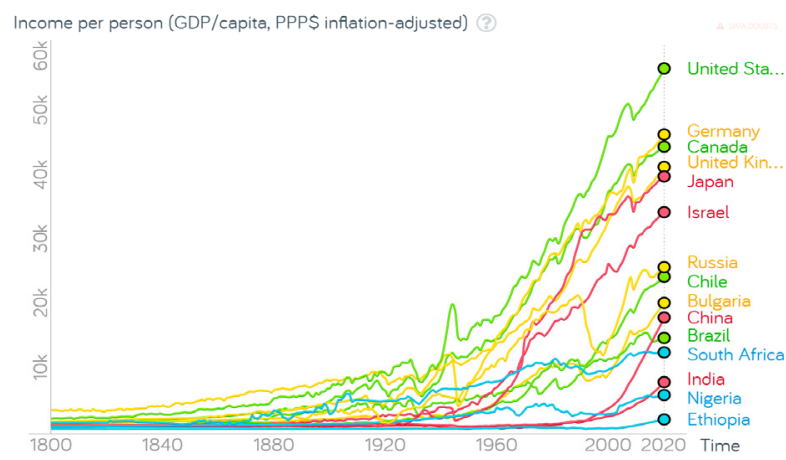

Fig. 3. Graphic of the income per person. (Source: Gapminder Tools)

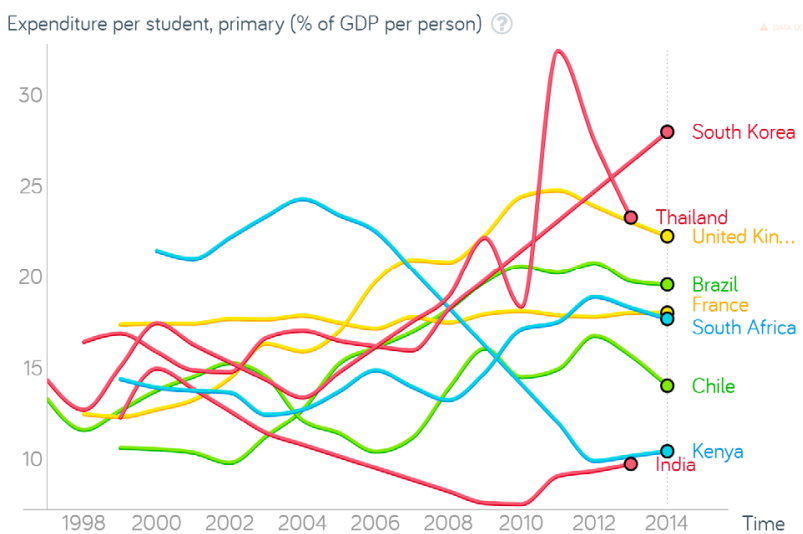

Fig. 4. Graphic of the inequality index. (Source: Gapminder Tools)

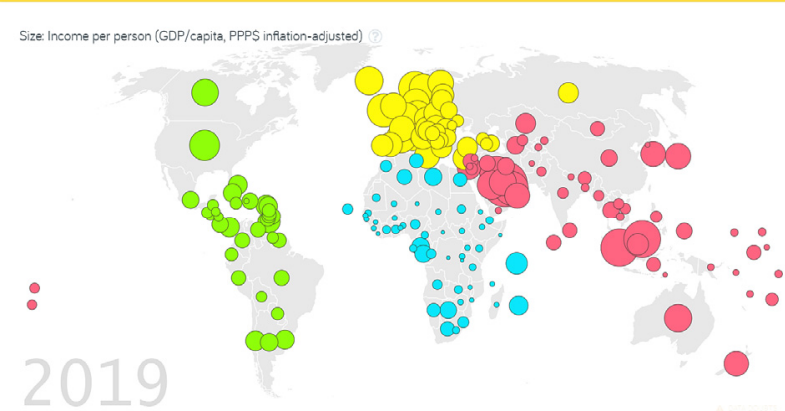

Fig. 5. Graphic of the size of income per person around the globe.

(Source: Gapminder Tools) 
Above is the map of data about the income per person around the world. Besides, our group also found that a large number of countries did not give out their Gini index in recent years. Hence, the public normally do not have access to the true official information and data of inequality. Below is the more accurate data, which indicates greater inequality can also affect the environment, as those at the upper end of the income distribution may be able to shift the environmental costs of their lifestyles and consumption decisions to those at the lower end. (GSDR Report 2019)

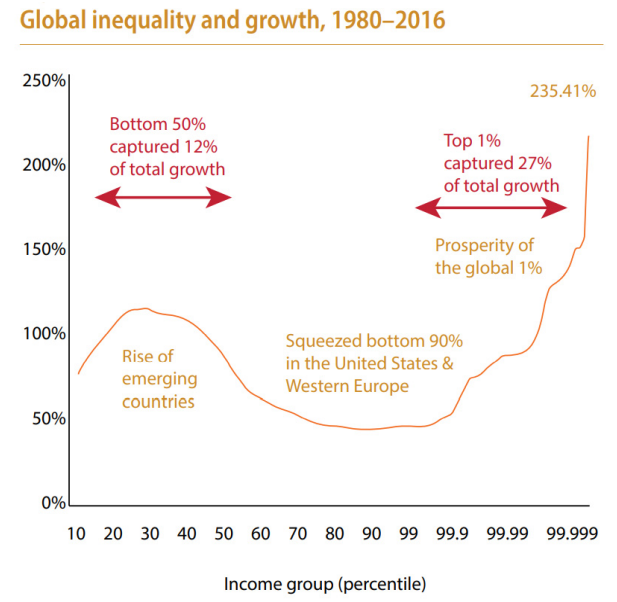

Fig. 6. Graphics of the global inequality and growth. (Source: Alvaredo, Facundo, et al., 2018; Corak, 2013)

Intergenerational mobility and inequality

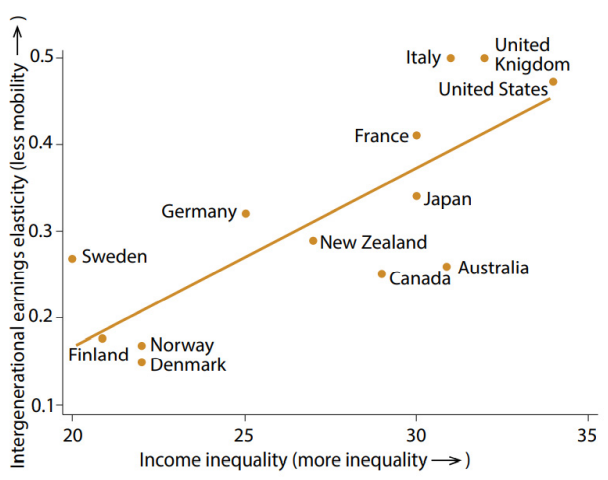

Fig. 7. Graphics of the intergenerational mobility and inequality. (Source: Alvaredo, Facundo, et al., 2018; Corak, 2013)

\subsection{Graphics of Changing Trend of The Climate Change}

Considering the special nature of this problem, researchers tend to choose different areas for observation. The graphics in this part are just for reference only. We will discuss it more specifically in the following dimension of the essay.

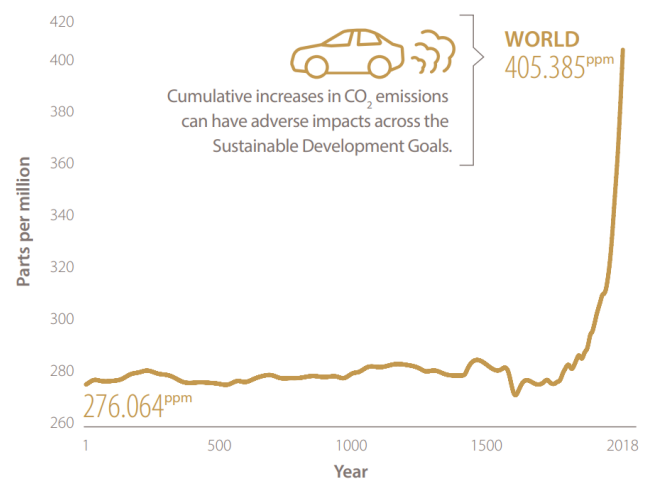

Fig. 8. Graphics of the human activity inducing climate change: rising $\mathrm{CO}_{2}$ levels

(Source: Macfarling Meure, C., et al., 2006; World Meteorological Organization, 2019)

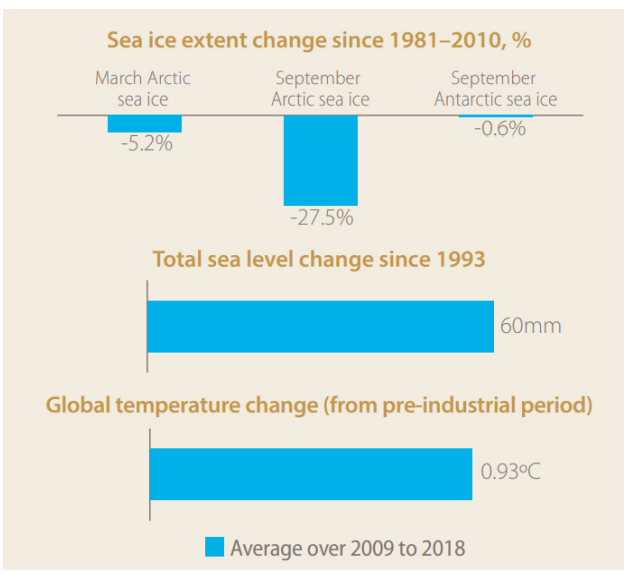

Fig. 9. Graphics of the human activity inducing climate change: increasing mean temperatures, shrinking sea ice, elevated sea levels

(Source: Macfarling Meure, C., et al., 2006; World Meteorological Organization, 2019)

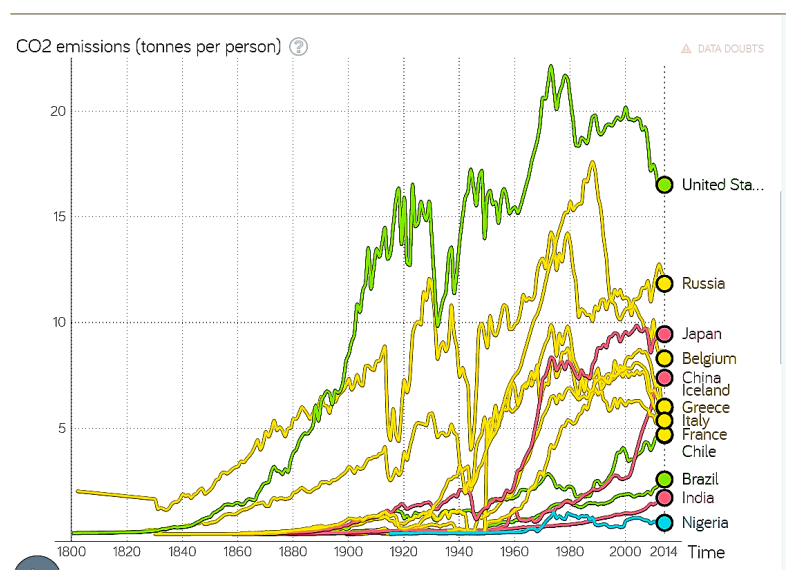

Fig.10. Graphics of the $\mathrm{CO} 2$ emission of different countries.

(Source: Gapminder Tools)

The pictures above have shown the strong relationship between $\mathrm{CO} 2$ emissions and the climate change. The research team would like to discuss the internal connection among $\mathrm{CO} 2$ emissions, climate change and the expenditure on environmental issues. Then the researchers need to find out why the environmental problems are not getting better. 


\section{DISCUSSION \& CONCLUSION}

\subsection{Proposed Question 1}

Children Education: Why it achieved a lot and what is the future vision?

A child's education differs from other developmental parts in that this part of development is, on the surface, subjective. There appears to depend on the will and capacity of governments and relevant institutions. The education policy of the government tends to increase household welfare, consisting compulsory education and investment in the education area, irrespective of the degree of development of a country. Moreover, public education policy is an optional way for poorer countries which can catch up with developed countries [1]. With the number of countries which adopt policies on sustainable development tending to grow, it has been proved that input for basic education is increasing and continue to be beneficial to enhancement the long term.

As shown in the table above, with the economic development of various countries, the proportion of national input and expenditure on children's education in the national total GDP shows a rising trend. This shows that education, especially basic education, is increasingly becoming a must for governments around the world.

Benefit from welfare of sustainable development strategy and basic education, more countries are taking delight in supplying the policy. People and organizations, such as United Nations, also tend to be optimistic to the future vision of children education. It can be predicted that in the near future, with the deepening of the concept of sustainable development, basic education will continue to receive financial support and policy support from the government. It is expected to achieve general access to basic education in most of the countries within the 2030 UN development cycle. Particularly, low- and middle-income countries are expected to facilitate highquality education in sustainable development in their schools [2].

\subsection{Proposed Question 2}

Equality in Income: The changing trend of inequality and what is the connection with the economic growth?

Equality in Income: The changing trend of inequality and what is the connection with the economic growth?

As can be seen from the chart in the last part, the economy of the international community has developed rapidly in the past 20 years. Due to the influence of globalization, the goods of various countries can circulate with each other, forming the world trade system with developed countries as the main body. Modernization theory explains this phenomenon well. The theory of modernization is used to explain the process of modernization within a society. It tries to explain how a society advances, what variables influence such progress, and how the society responds to such progress.

By the end of the Second World War, many countries in Africa, Asia and Latin America were still poor. The leaders of the western developed countries, especially the United States, worried about the influence of communism. Against this background, modernization theory was developed in the late 1940s with the aim of providing a concrete non-communist solution to poverty in the developing world.

To develop, less developed countries basically need to follow a development path similar to that of the West. To promote economic growth, they needed to adopt western cultural values and industrialize. To do so, they need the help of Western governments and companies, in the form of international aid and investment.

However, such rapid development is only the development of human society or the international community as a whole. At the micro level, economic inequality in each country is gradually widening. Against this backdrop, international development takes on an odd aspect: on one side are the rapidly growing riches of the advanced capitalist countries and on the other are the more decaying third-world countries. Then the dependency theory emerged.

The relationship between developing countries and developed countries is one of dependence, exploitation, and pillage. In the world economy, there is a central peripheral hierarchy. The developed capitalist countries constitute the centre of the world economy, while the developing countries are in the periphery of the world economy and subject to exploitation and control by the developed countries.

This circumstance can be interpreted by Dynamic Models of Segregation, or Schelling Model. Based on agent model, Schelling Model is an abstract pattern of the interactive dynamics of discriminatory individual choices, which reflects the irrelevant relation between individual incentive and collective results, while systemic effects are found to be overwhelming. Micro behaviour may differ from the macro condition, as a result [3].

When analysing the world economy pattern with Schelling Model, the reason why disparity of countries is enlarging can be explained.

Research community commonly analyse economic and racial segregation as sample. Similar race or income group attempt to inhabit together in a region, because of the sense of identity and security provided by similarity of habits, culture, and relative elements, which means people are also willing to move to area with same race.

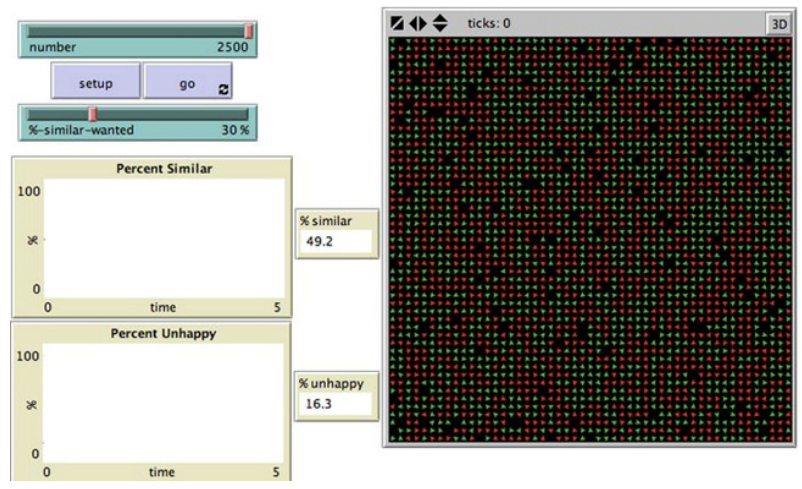

Fig. 11. Graphics of Schelling isolation model.

(Source: https://www.coursera.org/learn/model-thinking) 
The experiment was designed by Net Logo. It was based on 2500 points, assumed as individuals, divided only by high-income and low-income group. The individuals would be unhappy and seek to move if there are more than $70 \%$ neighbourhoods differ from themselves, which is the threshold value in first section.

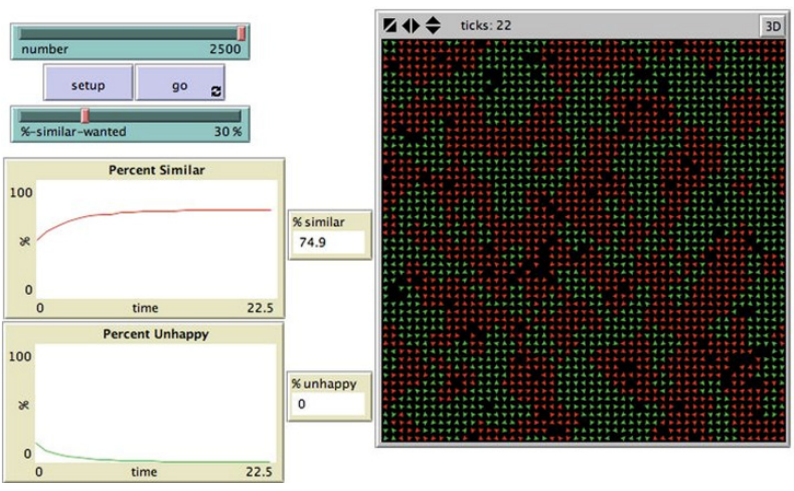

Fig. 12. Graphics of Schelling isolation model.

(Source: https://www.coursera.org/learn/model-thinking)

These assumptions result in that people have $74.9 \%$ similar neighbours on average, causing the accumulation of people.

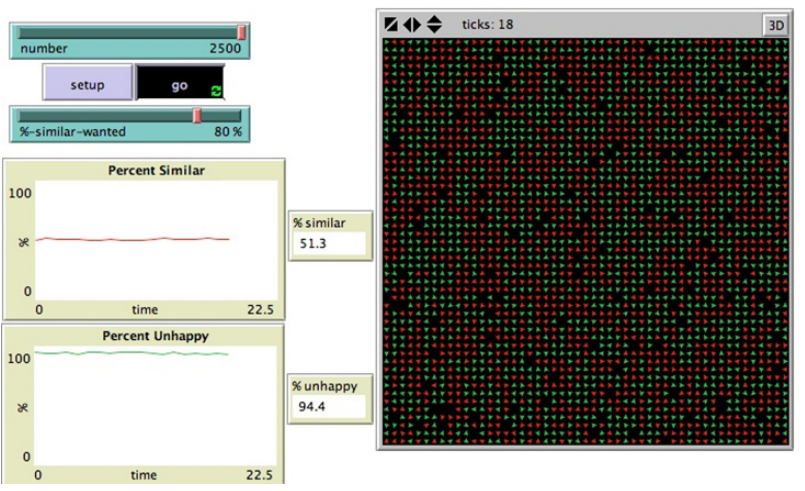

Fig. 13. Graphics of Schelling isolation model.

(Source: https://www.coursera.org/learn/model-thinking)

Reduce the threshold value of unhappiness to $20 \%$ as the second section, which means people will be willing to move if more than $20 \%$ neighbourhoods are different. Result based on this assumption is unequal, showing no segregation continually.

For the outcome of experiment, it is sufficient to point out that with changing of the condition, such as higher request, macro behaviour may be not related to micro choice, even tend to be opposite. With lower request for neighbours, segregation is shaped as a result, and higher request leads to no segregation on the contrary.

Based on Dependency Theory, the expansion of economic inequality can be analogized as section 1 in the experiment. Affected by requirement of industrial agglomeration and accumulation of industrial factors, scale of fundamental industries will tend to expand in developing countries, while tech-oriented industries can develop in industrialized countries similarly.

However, with the growth of globalization, cooperation and dependency relations between nations are enhanced during this process. This caused the Siphon effect between countries, which tends to cause the exploitation to developing countries while enlarge the interests that benefit industrialized countries to a large extent, and prevent the industrial evolution for fundamental industries and, as a result, expand the segregation.

Dependency is a historical condition that forms a structure of the world economy that favours some countries over others and limits the development possibilities of dependent economies. And that is why the relationship between economic development and inequality has not shown a positive correlation in recent years.

\subsection{Proposed Question 3}

The Climate Change: Why the part have stalled or even regressed?

Ninety percent of the world's disasters are weatherrelated, climatic, or water related. Natural disasters cannot be prevented, but early warning can reduce the scale of a disaster. The World Meteorological Organization's Global Observing System, which reduces disaster risk by providing information for early warning and emergency response, has helped to reduce human deaths due to natural disasters in recent decades.

Environmental Kuznets curve shows that economic development initially leads to environmental degradation, but when the economy grows to a certain level, society begins to improve its relationship with the environment and the degree of environmental degradation decreases.

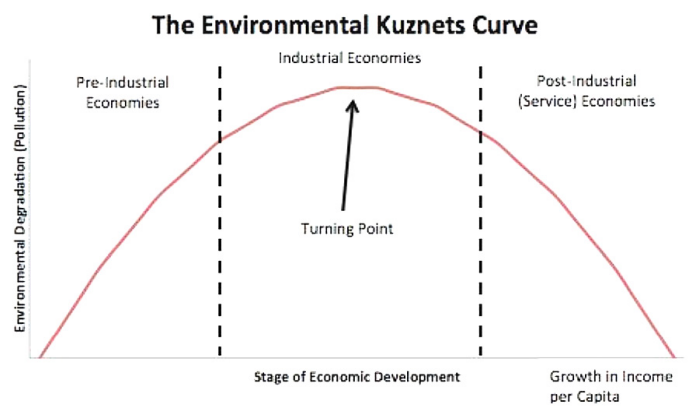

Fig. 14. Graphics of the Environmental Kuznets Curve.

UN Secretary-General Antonio Guterres and World Meteorological Organization (WMO) Secretary-General Pettiri Talas jointly released the 2019 Global Climate Statement at a UN press conference on 10 March 2020.

According to the statement, 2019 was the second warmest year on record. The period from 2015 to 2019 has been the warmest five years on record, while the period from 2010 to 2019 has been the warmest 10 years on record. Each successive decade since the 1980s has been warmer than the previous one since 1850 .

One of the biggest impacts of climate change is on water, which in turn affects sustainable development and security. But unlike coordinated international information on warming, data on water resources are fragmented and incomplete. This year's World Water 
Day and World Meteorological Day are therefore focused on climate and water. One of the underlying themes is that we cannot manage what we do not monitor and measure -- and that is unfortunately the case with the ongoing coronavirus (COVID-19) pandemic.

The fundamental reason for the stagnation or even regression of the sustainable development goals of climate change is the contradiction between economic development and ecological footprint. So far, environmental problems have always arisen along with economic development. It should be pointed out that impacts on ecosystems, natural resources, economic activities, and human welfare, depend on a wide range of changes in the environment besides only climate change, and, significantly, the capacity of societies to abate and adapt to these impacts in case of fragility and adaptive capacity. Intensive integration is required to address feedback circle and specific issues such as policies which can exert implications on ecological and economic for adaptation impacts on human well-being [4].

Countries and governments seem unable to find an effective way to control the ecological footprint of human beings while developing their economies. In the UN 2019 report, the organization has mentioned 4 levers which are governance, economy and finance, individual and collective action and science and technology. These are the solutions to the 6 entry points: Human wellbeing and Capabilities, Sustainable and just economies, Food systems and nutrition patterns, Energy decarbonization with universal access, Urban and periurban development and Global environmental commons. About the last one (Global environmental commons) which relates to the climate change, we need to strictly adopt relevant global regulations.

Access to global environmental Commons (biodiversity, land, atmosphere, and oceans) is essential, but they are being exhausted and degraded, with effects that transcend national boundaries. There is therefore an urgent need to manage how natural resources are extracted from global public resources and how the resulting wastes are managed. The global environmental Commons are intrinsically linked, and they ignore national boundaries. The resilience and resilience of the earth system means feedback effects between expected public resources to maximize the common good and minimize trade-offs at the global and local levels. Management of the global Commons must explicitly address environmental injustices, avoid unequal use of resources, and repair the damage already done through a combination of technical, financial, and political interventions.

It is foreseen that, in the short term, environmental problems may remain in conflict with economic development without significant improvement. However, if all countries and international organizations are willing to work together, sacrifice part of their economic interests together, and actively take measures to improve the ecological footprint, the trend of climate change will surely be slowed down, and ecological sustainable development will finally be realized.

\subsection{Conclusion}

The Sustainable Development Goals and the 2030 Agenda for Sustainable Development posted a hopeful view and trend to work on, for both United Nations and every country. But with the research results mentioned above, it is sufficient to point out that gap is growing between what needs to happen and what is being done, compared with the optimistic goals, with only a minority of the 169 sub-targets are on track to fulfil the 17 higherlevel SDGs. [5]

Reasons to the sluggishness can be various. Limitations of the transformation between effective contribution and research to knowledge is remarkable, which prevents the actualization of goals. The lack of input to sustainability development and inequality of global science prevent the science of sustainability from reaching its full potential. Moreover, pressure of economic development, government expenditure, and international relationship also bring impediment to investment of sustainable development.

It can be summarized that although the reaching of sustainable development goals is facing difficulties, there are still numbers of optimistic results we receive. More attention has been put into sustainable area. For instance, climate change is being accepted globally, significantly in industrialized countries. Primary education is also being a remarkable issue especially for developing countries as an investment in long-term.

These improvements have brought more common view and make SDGs more acceptable around the world.

To make sustainable development a more practicable goal, multiple measures can be posted to improve its efficiency. We can acquire a better understanding of various trade-offs in human-environment system dynamics, which provides possibility both on reaching individual targets and producing synergies.[5] Also, connecting the global North and South is an essential mission which will arouse the transformational capacity of research, and share its gains equitably. Research to sustainable development should also be accounted, including the support of policy, founding, and infrastructure. Sustainable development is and will be an indispensable issue for our flourishing planet and human well-being.

\subsection{Limitation}

Due to the transient nature of the research process, researchers seldom use quantitative analysis to build relevant models for the research of this topic but use a large number of secondary data as supplementary materials. Therefore, the research of this topic may lack of direct investigation. Our group will work out a more reliable timeline and predict future international development trends in the future. This will help to increase the accuracy and objectivity of this research.

In the process of the essay, many of our beloved friends and researchers have supported us a lot. Here, we sincerely thank them at below for their hard work.

Research Leader: Parfait M Eloundou-Enyegue

TA: Mengyang Su 
Institution and Department: Department of Development Sociology, Cornell University

Moreover, our researcher Siyuan Deng intend to warmly thank Yanying Xiao for her caring accompany with him during the study of the subject. The golden memory is inevitably immortal.

Our researcher Jingxing Zhang is indebted to Hongxia Zhang and Qi Wang for their continuous support and encouragement during the research.

\section{References}

1. Chia-Hui Lu (2020). Child labor and compulsory education: the effects of government education policy on economic growth and welfare. Economic Theory, 69(3), 637-666. https://doi.org/ 10.1007/s00199-019-01176-w

2. Peter Messerli (2019), Endah Murniningtyas. Global Sustainable Development Report, 134. https://unstats.un.org/sdgs/report/2019/

3. Thomas C. Schelling (1971). Dynamic Models of Segregation. Journal of Mathematical Sociology, 1(2), 143-186. https://doi.org/ 10.1080/0022250X.1971.9989794
4. Moss, R.H., Edmonds, J.A., Hibbard, K.A., Manning, M.R., Rose, S.K., van Vuuren, D.P., Carter, T.R., Emori, S., Kainuma, M., Kram, T., Meehl, G.A., Mitchell, J.F.B., Nakicenovic, N., Riahi, K., Smith, S.J., Stouffer, R.J., Thomson, A.M., Weyant, J.P., \&Wilbanks, T.J. (2010). The next generation of scenarios for climate change research and assessment. NATURE, 463(7282), 747-756. https://doi.org/10.1038/nature08823

5. Messerli, P (Messerli, Peter); Kim, EM (Kim, Eun Mee); Lutz, W (Lutz, Wolfgang); Moatti, JP (Moatti, Jean-Paul); Richardson, K (Richardson, Katherine); Saidam, M (Saidam, Muhammad); Smith, D (Smith, David); Eloundou-Enyegue, P (Eloundou-Enyegue, Parfait); Foli, E (Foli, Ernest); Glassman, A (Glassman, Amanda); Licona, GH (Licona, Gonzalo Hernandez); Murniningtyas, E (Murniningtyas, Endah); Staniskis, JK (Staniskis, Jurgis Kazimieras); van Ypersele, JP (van Ypersele, Jean-Pascal); Furman, E (Furman, Eeva)(2019). Expansion of sustainability science needed for the SDGs. Nature Sustainability, 2(10), 892-894. 